\title{
Pituicytoma, Not a 'Meningioma': \\ Late Recurrence in a Rare Pituitary Tumour
}

Mahender Yadagiri ${ }^{1}$, Simon Shaw ${ }^{2}$, Natarajan Saravanappa ${ }^{3}$, John Ayuk ${ }^{1}$, Biju Jose ${ }^{1}$

Depts. of Diabetes \& Endocrinology ${ }^{1}$, Neurosurgery $^{2}$, ENT ${ }^{3}$
Royal Stoke University Hospital, Stoke-on-Trent, UK

\section{Background}

Pituicytomas are rare tumours, originating from modified glial cells called pituicytes. The lineage of these tumours remains a topic of debate. Approximately 65 cases have been reported in the literature, since being formally recognised in 2007.1

We report a case where the final diagnosis was made after second surgery for late recurrence.

\section{Case}

A 54-year old man presented with left sided visual disturbances in 1998 and underwent transcranial resection of a sellar/suprasellar lesion. Histology was atypical but was concluded as suprasellar meningioma following a second opinion. During surveillance over 15 years, the small residuum grew to cause optic chiasm compression.

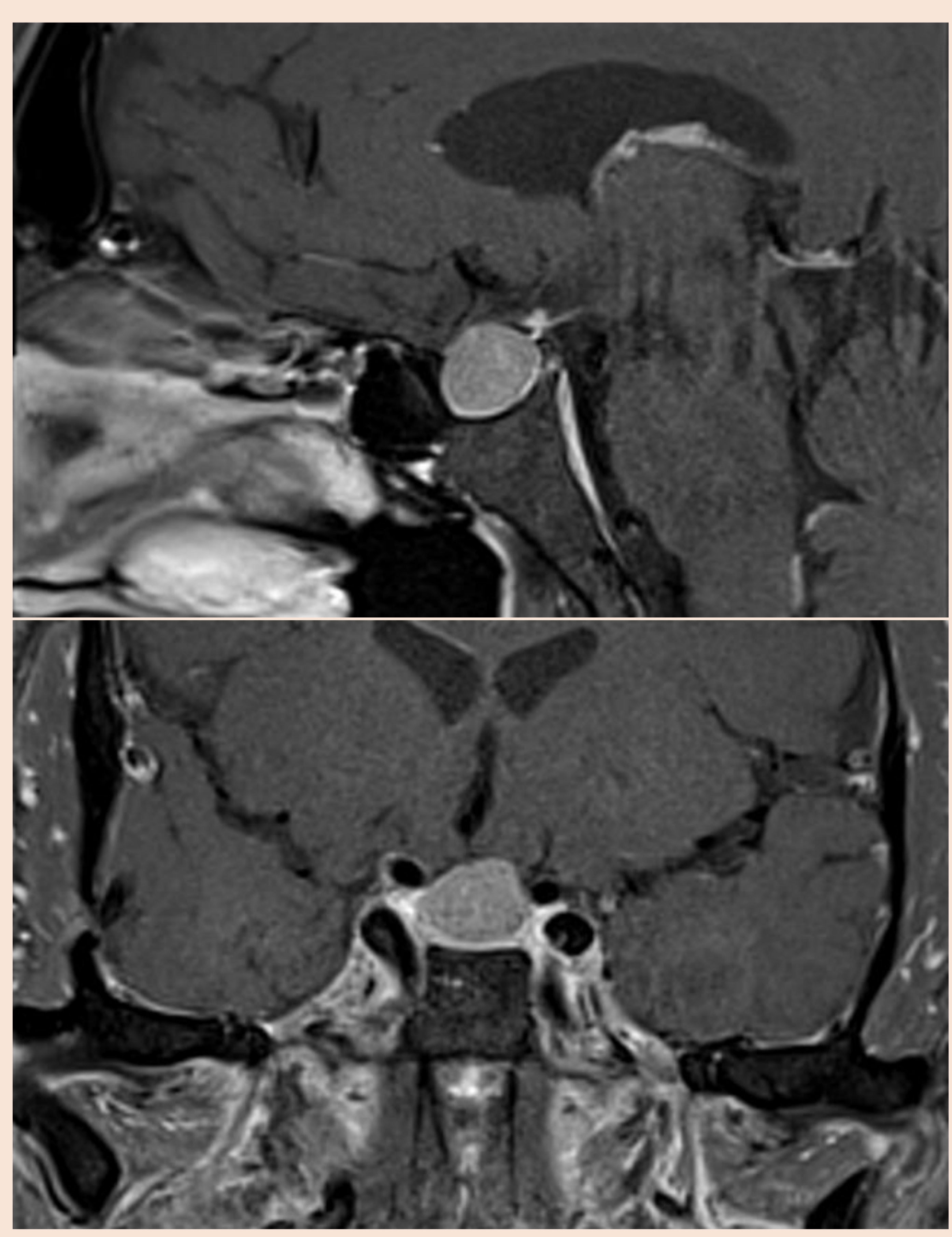

Tumour was removed endoscopically. The histology was compared with the 1998 sample and both were confirmed as pituicytoma, using newer immunohistochemistry methods.

\section{Discussion}

Pituicytoma was recognised as a distinct entity in 2000 and subsequently added to WHO-2007 classification of Tumours of Cranial Nervous System. Generally, these are slow-growing tumours. The presenting symptoms are due to mass effects, especially compression of optic chiasm. Clinical and imaging features are indistinguishable from other sellar tumours.

Microscopically, they are made of elongated bipolar spindle- or stellate-shaped cells with irregular nuclei and syncytial fibrillary cytoplasm. These tumors are characterized by a rich capillary network.

Immunostaining is often strongly positive for S-100, Vimentin and Thyroid transcription factor 1 (TTF-1), but negative for pituitary hormones and neuroendocrine markers like synaptophysin and chromogranin. ${ }^{2}$ TTF-1 is helpful in distinguishing pituicytoma (TTF-1 positive, as in this case) from meningioma, schwannoma and pilocytic astrocytoma, which are TTF-1 negative.

Definitive management is total resection, often hampered by the hypervascularity. Recurrence within a few years after subtotal resection is well-documented. However, our case recurred 15 years after near-total resection.

\section{Conclusion}

It is important to be aware that this rare, highly vascular tumour has the potential to re-grow even after a decade. Long-term clinical, neuro-ophthalmic and MRI surveillance is essential.

\section{References}

1. Louis DN, Ohgaki H, Wiestler OD, Cavenee WK, Burger PC, Jouvet A, et al. Scheithauer, Paul Kleihues. The 2007 WHO classification of tumours of the central nervous system. Acta Neuropathol 2007;114:97-109

2. Newly codified glial neoplasms of the 2007 WHO Classification of Tumours of the Central Nervous System: angiocentric glioma, pilomyxoid astrocytoma and pituicytoma.Brat DJ, Scheithauer BW, Fuller GN, Tihan T. Brain Pathol. 2007 Jul; 17(3):319-24. 